\title{
GÉNESIS DE UNA IDENTIDAD VISUAL: CREACIÓN DE LA IMAGEN PARA EL CONGRESO INTERNACIONAL DE PATRIMONIO ALIMENTARIO Y MUSEO
}

\author{
Maricha Martínez Sosa \\ República Dominicana.info@marichams.com
}

\begin{abstract}
Graphic design, when assumed professionally, is a research process from which visual results are obtained. This paper addresses the connection between graphic design and intellectual production for academic purposes, and presents the concept of design methodology. From the methodological perspective, and following the 5 steps of the scientific method, the process and motivations behind each decision are presented, detailing the approach to the project for the creation of the visual identity of the Congreso Internacional de Patrimonio Alimentario y Museos El Gusto en el Museo (EGEEM). By taking as an example the way in which the visual identity of this congress was developed, readers are allowed to witness the process that led to its creation, and the brushstrokes that can serve as a guide for the development of projects with similar characteristics are laid.
\end{abstract}

Keywords: communication, brand, corporate, graphic design, identity, image, manual, methodology, research.

Resumen: El diseño gráfico, cuando se asume de forma profesional, es un proceso de investigación del cual se obtienen resultados visuales. En este documento se aborda la conexión que tienen el diseño gráfico y la producción intelectual con fines académicos y se presenta el concepto de metodología del diseño. Desde la perspectiva metodológica y siguiendo los 5 pasos del método científico, son presentados el proceso y motivaciones detrás de cada decisión tomada en el abordaje del proyecto para la creación de la identidad visual del Congreso Internacional de Patrimonio Alimentario y Museos El Gusto en el Museo (EGEEM). Al tomar como ejemplo la forma en que se realizó el desarrollo de la identidad visual de este congreso, se permite a sus lectores ser testigos del proceso que llevó a su creación y se dejan las pinceladas que pueden servir de guía para el desarrollo de proyectos con características similares.

Palabras clave: comunicación, corporativa, diseño gráfico, identidad, imagen, investigación, manual, marca, metodología.

Citar como: Martínez Sosa, M. (2022). "Génesis de una identidad visual: creación de la imagen para el Congreso Internacional de Patrimonio Alimentario y Museo". En: Actas del III Congreso Internacional sobre Patrimonio Alimentario y Museos. 25-26 noviembre, 2021, Valencia, España. pp. 99-118. https://doi.org/10.4995/EGEM2021.2021.13421 


\section{Introducción}

Las marcas que gozan o desean gozar de cierta estabilidad buscan formas de ofrecerle a sus clientes, audiencias o usuarios una imagen sólida y coherente que comunique sus valores y principios. Estas deben poder ser representadas en todos sus productos y estar presentes en los distintos momentos y puntos de contacto. La creación de una imagen corporativa es, como indica el título de este artículo, la génesis de una identidad visual pues su correcto desarrollo conlleva entrevistas, indagación, experimentación y prueba y error. Hay quienes pecan de entenderla como algo sencillo y fácilmente automatizable, obviando que, más que convertir la inspiración de las musas en trazos vectoriales o píxeles, asumir la creación de una imagen es embarcarse en un problema de investigación cuya solución aplica muchos, si no todos, los pasos del método científico.

Como dato curioso, cabe destacar que no es tan común encontrarse con publicaciones del resultado de una imagen de marca ya que estas suelen limitarse a los manuales de identidad corporativa, los cuales son generalmente de uso interno. Esto se aplica no solo en el área de alimentación, sino al diseño de identidad corporativa en general. Con base en la experiencia profesional como diseñadora gráfica por más de una década, quien suscribe intuye que esto se debe, entre otras, a dos razones:

1. Que el diseñador rara vez tiene la oportunidad de publicar respecto a su proceso creativo, pues son escasos los medios destinados a estos fines y no existe una cultura de producción intelectual académica en este gremio.

2. Que honrar los acuerdos de confidencialidad cliente-proveedor limita significativamente los derechos editoriales sobre el trabajo resultante de las creaciones gráficas.

Ante esto se entiende prudente iniciar con la síntesis de una evaluación de la relación del diseño gráfico con la publicación académica. Analizar cuáles han sido, históricamente, las posturas dominantes en torno al desarrollo de una metodología del diseño y qué tan común es el tipo de análisis que pretende hacerse en las siguientes páginas.

Para entender si es correcta la percepción de que, efectivamente este tipo de publicaciones no es la norma, el presente documento muestra el concepto de metodología del diseño y une múltiples ideas en torno al mismo. Se toma como ejemplo la forma en que se realizó el abordaje del desarrollo de una identidad visual que vincula al diseño gráfico con la alimentación, la museografía y la producción académica. Permitiendo que la audiencia misma de su producto resultante, por tratarse en este caso de la imagen de este congreso, sea también testigo del proceso que llevó a su creación.

Luego de vincular el binomio diseño gráfico - metodología se describe el proceso de creación de una identidad visual particular y se utiliza la imagen del Congreso Internacional de Patrimonio Alimentario y Museos El Gusto en el Museo (EGEEM) como ejemplo y guía. Se presenta un análisis, desde la perspectiva metodológica, del proceso y motivaciones detrás de cada decisión tomada en el proceso de creación de esta identidad, y se dejan pinceladas que pueden servir de guía para el desarrollo de proyectos con características similares.

En el presente documento se abordan preguntas como:

¿Qué conexión tienen el diseño gráfıco y la producción intelectual con fines académicos? 
¿Cómo se aborda el diseño de una marca que abarca diversas áreas temáticas y que pertenece a un entorno institucional?

¿Cómo abordar proyectos que ya son conocidos y tienen una reputación?

\section{Objetivos}

\subsection{Objetivo general}

Presentar el proceso de creación de una pieza de diseño gráfico como ejercicio de producción académica, tomando como ejemplo la creación de una identidad visual vinculada con la museografía y alimentación.

\subsection{Objetivos específicos}

- Demostrar que el diseño es un proceso de investigación que se vale de los pasos del método científico.

- Analizar la relación histórica del binomio diseño gráfico - producción académica.

- Ilustrar la metodología de diseño utilizada para la creación de una imagen visual, la del Congreso Internacional de Patrimonio Alimentario y Museos El Gusto en el Museo (EGEEM).

\section{Desarrollo de la innovación}

Para conectar al diseño gráfico con la producción intelectual con fines académicos y la alimentación, se analizarán antecedentes de la relación diseño - investigación. Se presentará el diseño de una identidad visual y se tomará como caso de análisis el desarrollo la realizada para la serie de conferencias sobre patrimonio alimentario en las cuales se enmarca este artículo.

\subsection{Metodología del Diseño: antecedentes}

El deseo de 'cientificar' el diseño se remonta a las ideas del movimiento moderno de la década de 1920. Benet (2006) describe que "los primeros ejemplos de investigación empírica en la historia del diseño gráfico fueron cuando, en 1923, Wassily Kandinksy realizó un experimento de investigación sobre la relación del color con la forma en la percepción humana [...] Sus descubrimientos contribuyeron al modernismo y a la perspectiva ontológica de que la interpretación del lenguaje visual es universal en todas las culturas".

Sin embargo, la aparición de los que serían considerados como "nuevos métodos de diseño" data de algunas décadas después. Según afirma Nigel Cross en su obra "Science and Design Methodology: A review" (1993), en el período de 1950-1960 estas ideas fueron ganando popularidad hasta consolidarse a modo de concurridas conferencias y diversas publicaciones impresas. Y, hacia 1962, fue realizado en Londres un evento que dicho autor considera "el nacimiento de la metodología de diseño moderna y del movimiento de métodos de diseño". Inicialmente, estas líneas de pensamiento se centraban en el hecho de que la ciencia se ocupa de lo que existe, mientras que al diseño le atañe lo inmaterial y lo que ha de ser creado. Desde los primeros días, las metodologías de diseño han tratado de establecer distinciones entre el diseño y la ciencia. 
Un ejemplo es la cita de Gregory (1966) afirmando que: mientras "la ciencia es analítica; el diseño es constructivo".

La dicotomía expresada en los años 60 fue sustituida por un reconocimiento más complejo de la red de interdependencias entre el conocimiento, la acción y la reflexión. Y ya para la década de 1970 reconocidas voces se elevaban en rechazo de los intentos de encajar la creatividad en frameworks y métodos estandarizados. Hay quienes presentaron puntos de análisis contrastados de la relación entre ciencia y diseño. De los escritos de Grant (1979), se extraen frases como que "el acto de diseñar en sí mismo no es ni será nunca una actividad científica", pero que su estudio sí. "Es decir, el diseño como actividad puede ser objeto de investigación científica".

Otros, como Green (1985), señalaron que los científicos, al igual que los diseñadores, crean sus hipótesis y teorías y las utilizan para orientar su búsqueda de información. También en 1985, Levy invitó a ver la ciencia más como una "racionalidad expandida para la identificación de problemas estructurales y la resolución de actividades [...] haciendo que la metodología científica suene indistinguible de las metodologías de diseño". Y hacia 1990 Willem afırmaba que "el diseño hace a la ciencia visible", destacando que los orígenes de los métodos de diseño se encuentran en los métodos científicos y que los resultados del diseño solo existen gracias a ser aplicaciones de la ciencia.

Por su parte, Cross (1993) invita a hacer una distinción crítica ante la idea de que "el método puede ser vital para la ciencia (donde se validan los resultados) pero no para el diseño (donde los resultados no tienen que ser repetibles)". Señalando también que no existe un método de diseño único y universal, basado en lenguajes y teorías formales ${ }^{1}$ y afirmando que: La ciencia del diseño aborda el problema de determinar y categorizar todos los fenómenos regulares de
los sistemas que se diseñan y del proceso de diseño. [...] Se refiere a un enfoque explícitamente organi-
zado, racional y totalmente sistemático del diseño; no sólo la utilización del conocimiento científico de
los artefactos, sino el diseño en cierto sentido como una actividad científica en sí misma. Por tanto, la
ciencia del diseño es el estudio del diseño.

Sobre la metodología y la ciencia del diseño, el mismo Cross (1993) destaca que:

La ciencia del diseño se refiere al conjunto de trabajos que intentan mejorar nuestra comprensión del diseño mediante métodos "científicos" de investigación. [...] Incluye el estudio de cómo trabajan y piensan los diseñadores, el establecimiento de estructuras adecuadas para el proceso de diseño, el desarrollo y la aplicación de nuevos métodos, técnicas y procedimientos.

\subsection{Diseño e investigación}

Cuando se habla de investigación es prudente recurrir a uno de los más destacados autores de habla hispana: Roberto Hernández Sampieri (2014), quien la define como "un conjunto de procesos sistemáticos, críticos y empíricos que se aplican al estudio de un fenómeno o problema". Es bien entendido que el desarrollo de una investigación se vale del método científico, el cual es definido por Gargantilla (2020) como "un conjunto de pasos ordenados que se emplean para adquirir nuevos conocimientos". Una mirada crítica permite apreciar que las aplicaciones del método científico trascienden la ciencia pura y pueden ser ampliamente encontradas en la vida cotidiana. Y, aunque la forma de llamarle a las etapas del método científico pueden diferir entre

\footnotetext{
Como una de las primeras generaciones de licenciados egresados de la carrera de Diseño Gráfico, quien suscribe verifica la validez de estas ideas de Cross a la fecha de sus estudios formales de grado, los cuales fueron realizados entre 20032008 en la Universidad Apec de la República Dominicana.
} 
un autor y otro, es ampliamente entendido que consta de 5 pasos: observación, formulación de hipótesis, experimentación, emisión de conclusiones y publicación.

Para abordar la investigación desde la mirada del diseño gráfico se recurre a Heller (2006) quien afirma que más que tener una teoría que requiere ser probada y examinada desde varios puntos de vista para lograr un resultado, en el caso que nos atañe el resultado rige la forma en que se ejecutará una solución de diseño. Por todo lo anterior, para los fines de este artículo se asume como correcta la afirmación de Bennett (2006) de que los diseñadores gráficos son en realidad productores de conocimientos interdisciplinarios, y no sólo traductores visuales de las necesidades, conocimientos y expectativas de un cliente. Se entiende además como verdad, que el diseño se vale del método científico de forma inherente y que los diseñadores hacen uso de sus pasos ya sea de manera consciente o inconsciente.

Finalmente y partiendo de que lo que se hará es teorizar sobre soluciones gráficas, habría que definir ¿en qué consiste teorizar sobre diseño? Para ello, vale rescatar lo expresado por Bennett (2006): "tradicionalmente, la teoría del diseño gráfico ha privilegiado la intuición y la creatividad sobre la investigación empírica”. De hecho, ante la pregunta de "¿cuáles son las teorías del diseño gráfico?" esta académica aborda interesantes posturas como que:

Se puede argumentar que los principios del diseño gráfico basados en el arte -incluyendo (pero no limitándose a) el contraste, la jerarquía, la repetición, la alineación y el color- son de hecho teorías probadas a través de una larga historia de experimentación exitosa en la práctica. Sin embargo, dentro de la disciplina del diseño gráfico estos principios no se consideran teorías "probadas", porque el diseño gráfico carece históricamente de una agenda de investigación sólida. Por el contrario, el diseño gráfico -en parte debido a su aglomeración artística- ha desarrollado una reputación de práctica alimentada por la intuición, basada principalmente en el talento.

Sobre la producción bibliográfica dentro de la disciplina del diseño, la misma Bennett (2006) afirma que salvo notables distinciones, esta se ha limitado a analizar diseños en el mercado y a alimentar la experiencia práctica profesional. Que pese a la existencia de:

Revistas académicas que informan de los resultados de la investigación y de las perspectivas teóricas sobre temas de diseño gráfico [...] debido a su naturaleza intuitiva, los profesionales del diseño gráfico no han seguido el ejemplo de sus académicos. En su lugar, existe un abismo intelectual entre la práctica y la investigación [..] Pocas veces, o ninguna, el contenido real está escrito por los diseñadores gráficos que produjeron la estética, en parte porque los diseñadores gráficos no suelen tener el control editorial de su trabajo.

Así pues, esta puede ser considerada una de esas raras veces en las que un equipo de diseño tiene el privilegio de presentar su trabajo y de reivindicar, en cierto modo, el silencio habitual de casi todo un gremio.

\section{Resultados}

Dentro del proceso agotado para la creación de la imagen de EGEEM se optó por seguir un estilo democrático y fundamentado en el análisis. Sobre este, la autora Elizabeth Throop (2006) afirma que: "aboga por un proceso de diseño más riguroso, basado en la investigación, que no se limita a preguntar al público lo que piensa de un prototipo de diseño", haciendo alusión a que va más allá de presentar opciones finales y que busca involucrar al cliente. Por su parte Bennet (2006) afirma que: 
"La disciplina del diseño gráfico debe equilibrar su meritocracia con una democracia que dé poder a todos los participantes [...] Los enfoques colaborativos del diseño facilitan un proceso de diseño democrático que valora las diversas opiniones y fomenta la participación del público [...] incluyen la participación, el contexto y otros subconjuntos del diseño centrado en el usuario.

En la experiencia profesional de quien suscribe, la gran mayoría de las veces no se hace al cliente parte del proceso de decisión hasta casi el final, cuando se le presentan dos o tres propuestas a elegir. En el caso particular de EGEEM, se integró al equipo coordinador del congreso de distintas formas:

- A través de sus insights.

- Con la expresión de sus gustos.

- Escuchando y entendiendo su visión del proyecto.

- Vía su retroalimentación sobre las propuestas.

- Dándoles el poder de la decisión final.

\subsection{Fase de Observación}

En un proyecto gráfico la fase de observación conlleva analizar la empresa, entidad o proyecto, su estructura y objetivos. Estudiar la competencia e identificar las tendencias de la misma. Escuchar (o leer, en caso de que se haga de forma asíncrona) las respuestas del cliente a cada pregunta. En este paso el equipo de diseño debe estar preparado para leer entre líneas y anteponer siempre las necesidades del cliente. Considerando que estas últimas incluyen tanto las necesidades que son claramente expresadas, como las que se hacen evidentes al ojo experto en cada interacción y ante cada pesquisa.

El desarrollo de una marca puede implicar desde la creación de sencillos elementos únicos, hasta complicadas intervenciones técnicas. Puede ser tan simple como una sola pieza o tan compleja y minuciosa como sea posible imaginarse. Por ello, junto a la aprobación de los términos de contratación es necesario determinar la amplitud del abordaje que desea hacerse.

\section{Primeros contactos}

El inicio del proceso agotado para la creación de la imagen de EGEEM tuvo los siguientes momentos clave: establecimiento de contacto, presentación del abordaje del proyecto, aprobación de los términos de contratación y definición de roles y equipo de trabajo. A continuación se detalla en qué consistieron:

- Establecimiento de contacto: se conversa con el cliente, por los medios de su preferencia, sobre sus necesidades y expectativas, se obtiene toda la información necesaria para preparar un acuerdo. Esto puede conllevar múltiples interacciones tales como llamadas, correos y reuniones.

- Presentación del abordaje del proyecto: se entrega el plan de trabajo incluyendo los tiempos estimados de desarrollo y, en caso de tratarse de un proyecto remunerado, se integra también el presupuesto.

- Aprobación de los términos de contratación: ambas partes acuerdan los términos de contratación, el plan de trabajo y el presupuesto (en caso de haberlo). Deben aclararse 
variables como la forma de pago, productos entregables, fechas clave y tipo de contrato, entre otras.

- Definición de roles y equipo de trabajo: como no todos los proyectos se abordan de igual forma, es prudente definir los roles tanto del cliente como del equipo. Mientras hay quienes tienen una idea clara de lo que quieren y solo necesita quien la ejecute, hay quienes tienen clara su necesidad, pero no las características de la misma. En este sentido, es válido cuestionar y aclarar con antelación si lo que se busca es quien ejecute de manera formalmente correcta mandatos o si, por el contrario, se desea un equipo creativo, crítico, analítico y con espíritu investigador.

Para el abordaje de EGEEM se optó porque el liderazgo del proyecto lo tuviera una dupla creativa de la República Dominicana constituida por quien suscribe, Maricha Martínez Sosa y el diseñador gráfico Sergio Elías Taveras.

\section{Banco de preguntas}

Para facilitar esta etapa del proyecto, junto al diseñador gráfico Sergio Taveras, se compiló una serie de preguntas, las cuales fueron retroalimentadas por la diseñadora Laura Angelina Calderón, en un esfuerzo de que el mismo fuera revisado por pares. Este cuestionario puede servir de guión para abordar un primer encuentro con el cliente y preparar un brief informado.

1. ¿Cuál es el nombre de la compañía?

2. ¿A qué se dedica la empresa?

3. ¿A quiénes van dirigidos los servicios o productos que esta ofrece?

4. ¿Cuál es la filosofía corporativa? (Misión, visión, valores)

5. ¿Qué intentó plasmar en el logo actual de su marca? (Si tiene uno actualmente)

6. ¿Qué significa el nombre de su empresa?

7. ¿A cuál tipo de logo aspira? Ejemplos

- Logotipo: Es la representación tipográfica o caligráfica de la marca.

- Símbolo o isotipo: Es la representación gráfica o visual de la marca.

- Logosímbolo o imagotipo: Es la combinación entre logotipo e isotipo.

- Isologo: Es la combinación de logotipo e isotipo, pero, no pueden ser desligados sin que pierdan su sentido.

- No lo sé.

8. ¿Cuáles logos de otras marcas son sus favoritos? (Agradecemos que comparta links donde podamos verlos)

9. ¿Cuáles logos del mercado NO le gustan? ¿Por qué? (Agradecemos que comparta links donde podamos verlos) 
10. ¿Qué desea representar en el logo?

11. ¿Cuáles atributos o elementos desea destacar en el logo?

12. ¿Cuáles atributos o elementos desea evitar en el logo?

13. ¿Cuáles colores NO le gustaría tener en su logo?

14. ¿Cuáles colores cree que son óptimos para representar su marca?

15. ¿Tiene algún tipo de tipografía (tipo de letra) de preferencia? Ejemplo: Serif / Sans Serif / Slab Serif

16. ¿No le gusta algún estilo de tipografía (tipo de letra)?

17. ¿Quiénes son sus principales competidores en el mercado?

18. ¿Para cuándo le gustaría que tengamos lista su solicitud?

Favor indicar la fecha idónea / deseada para la finalización de este proyecto.

19. Favor adjuntar cualquier archivo que considere pueda ayudarnos a entender mejor su negocio: imagen actual, referencias, etc.

Luego del inicio del proyecto de desarrollo de imagen para El Gusto en El Museo se agotaron tres pasos: lluvia de ideas, identificación de conceptos clave y comunicación de preferencias. Se inició con una reunión virtual con representantes del Congreso. En esta se escucharon las necesidades, deseos y objetivos. Luego de indagar sobre múltiples temas, se realizó la lluvia de ideas y se asumió como punto de partida la visión y posibles respuestas a la pregunta de: ¿qué se quiere comunicar? De ahí surgieron:

- Conceptos clave, como producción intelectual, alimentos, nueva museografía, visibilidad, miradas distintas e integración de los sentidos (Figura 1).

- Factores gráficos relevantes, como lo que no se deseaba. En este caso las directrices a nivel tipográfico incluyeron que la fuente a elegir no fuera serif, cursiva ni decorativa.

- Elementos gráficos de interés, como el socarrat y la cerámica de manises.

\section{Conceptos clave}

ALIMENTOS

NUEVA MUSEOGRAFÍA
LOS SENTIDOS

VISIBILIDAD /

MIRADA DISTINTA
SOCARRAT

CERÁMICA

(MANISES)

Figura 1. Conceptos clave.

Fuente: Elaboración propia. 


\section{Investigación de antecedentes}

A partir de ahí se inició una investigación para responder ¿qué se ha estado haciendo? Tanto en el caso particular de EGEEM como de otras entidades con algún tipo de similitud. Como este Congreso ya ha sido realizado anteriormente, se identificaron sus publicaciones previas, incluyendo el material de la convocatoria para la primera y segunda edición (Figura 2).

Luego se procedió a buscar referencias internacionales y locales. Dentro de las primeras se optó por destacar el Museum Of Food And Drink (MOFAD) y las jornadas gastronómicas realizadas por el Instituto Smithsoniano. Para el caso local se seleccionaron ejecuciones realizadas en Valencia (España) por L’Etno (Museo Valenciano de Etnología ) y por el Museu de Ceràmica de Manises (Figura 3).

A continuación se procedió a evaluar el contexto en el cual se enmarca el congreso: la Universidad Politécnica de Valencia (UPV), el Departamento de Comunicación Audiovisual, Documentación e Historia del Arte (DCADHA) y el Máster Oficial Interuniversitario en Gestión Cultural (Figura 4).
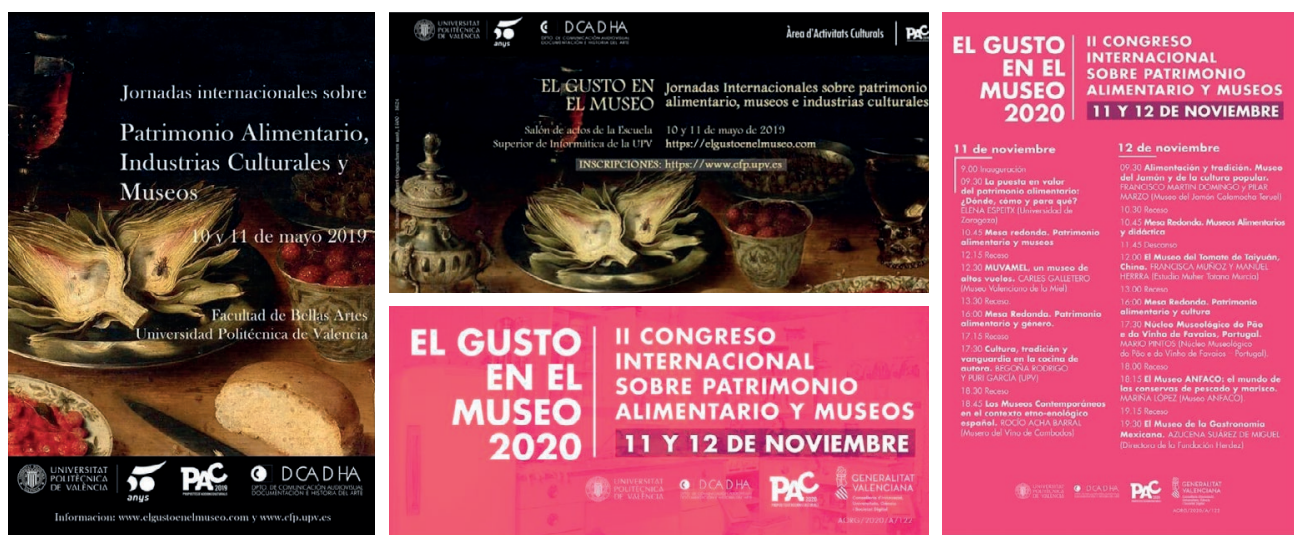

Figura 2. Composición de imágenes: antecedentes gráficos del proyecto. Fuente: Elaboración propia.
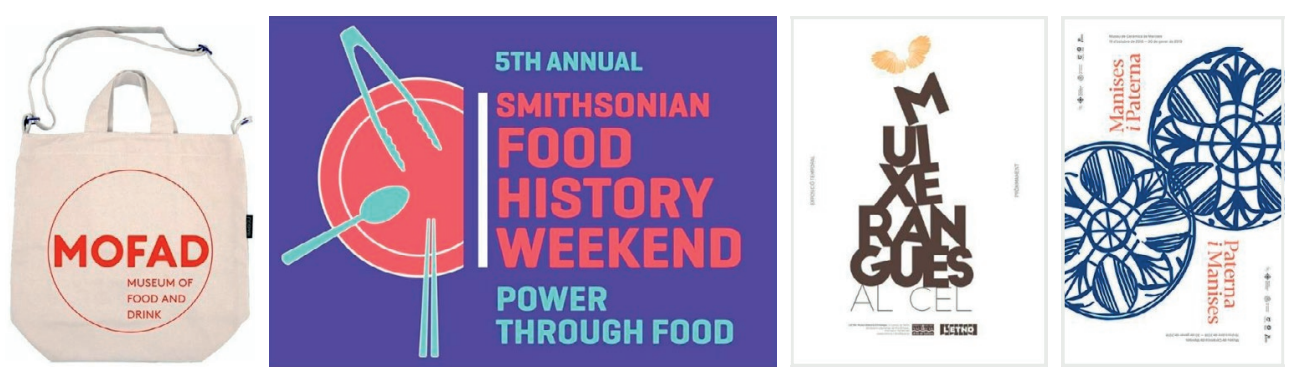

Figura 3. Composición de imágenes: referencias locales e internacionales.

Fuente: Elaboración propia. 


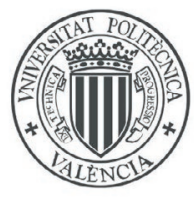

\section{UNIVERSITAT POLITĖCNICA DE VALÈNCIA}

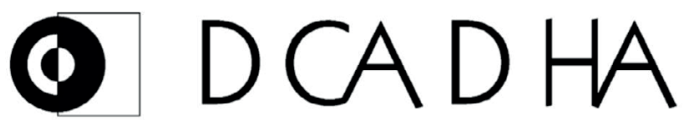

DPTO. DE COMUNICACIÓN AUDIOVISUAL DOCUMENTACIÓN E HISTORIA DEL ARTE

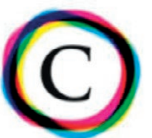
GESTIÓN CULTURAL Màster Oficial Interuniversitario

Figura 4. Composición de imágenes: contexto institucional en el cual se enmarca el congreso. Fuente: Elaboración propia.

\subsection{Fase de Formulación de Hipótesis}

Es probable que esta sea la etapa en la cual el diseño gráfico diste más de los resultados que tradicionalmente se obtienen de la producción intelectual. Más que enunciados escritos, lo que se obtiene en esta etapa es el racional, esa justificación conceptual que puede perfectamente ser entendida como la hipótesis que precede a lo visual. Aunque con frecuencia no se redacten, estas son las que establecen el punto de partida de las elecciones que se realizarán a continuación y al igual que otras hipótesis son sometidas a procesos de cuestionamiento, validación y, en caso de ser necesario, iteración.

\section{Concepto gráfico}

Se planteó la posibilidad de que el resultante de este proceso de diseño fuera un logotipo (representación tipográfica), un isotipo (representación gráfica o visual de la marca, sin texto) o un imagotipo (combinación entre logotipo e isotipo). Por ello, se optó por plantear un concepto gráfico que englobara múltiples significados: el ojo o la visión, la naranja de Valencia y el patrimonio cultural alimentario de la Cerámica de Manises.

Se plantearon propuestas, además con conceptos como cubertería, museo y el marco que suele acompañar las obras de arte expuestas.
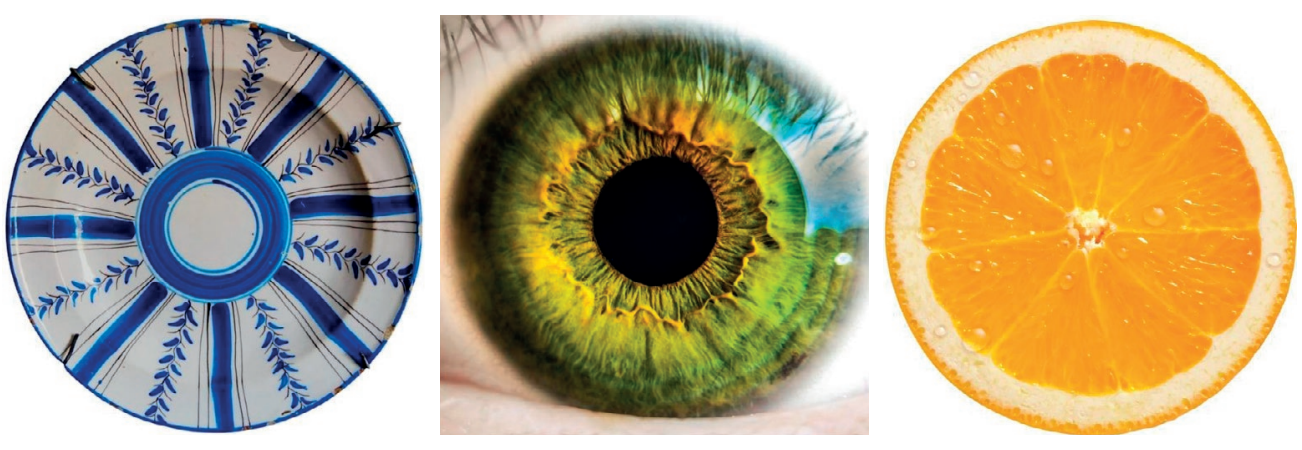

Figura 5. Conceptos visuales conectados. Fuente: Elaboración propia. 

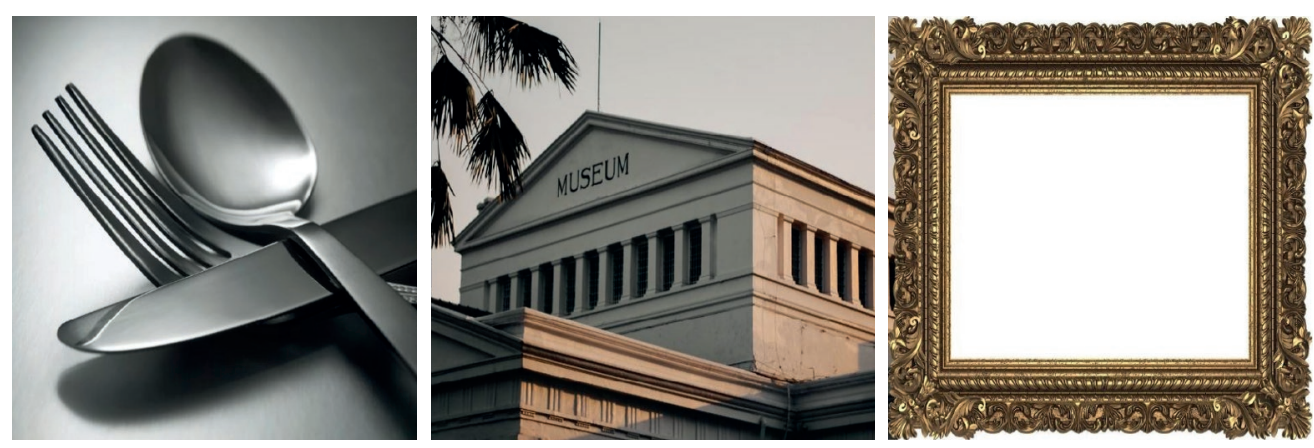

Figura 6. Conceptos visuales individuales.

Fuente: Elaboración propia.

\subsection{Fase de Experimentación}

Partiendo del racional establecido en la fase anterior, se integran el resultado de la investigación con la experiencia y la intuición. Esta combinación es la que define los criterios a utilizar durante las elecciones: tipográfica, cromática y estética, las cuales se detallan a continuación.

\section{Elección tipográfica}

Partiendo del 'feeling' descrito en la primera reunión, se inició la búsqueda de las distintas fuentes tipográficas que respondieran a los criterios acordados: san serif (palo seco), con aires de modernidad y fácil lectura. Se procuró además buscar tipografías que encajaran con los conceptos de gastronomía, museografía y producción intelectual.

La prueba realizada consistió en escribir en múltiples fuentes la frase "el gusto en el museo" en 3 versiones: mayúscula, tipo título y en minúscula. Las tipografías finalistas fueron: Kopius, Quiksand Bold, Dunbar Text, Semplecita Pro Medium, Atten New y Serenity Medium. Adicionalmente, se optó por la fuente Adorn Garland para la realización de experimentaciones con elementos en cursiva. La figura 7 muestra algunos de los ejemplos.

Se procedió entonces a seleccionar las favoritas del equipo de diseño y, finalmente, se optó por Serenity Medium como fuente primaria y Proxima Nova como fuente secundaria. La figura 8 presenta todos los caracteres que componen ambas tipografías.

Kopius

EL GUSTO EN EL MUSEO

El Gusto en el Museo

el gusto en el museo

Atten New

EL GUSTO EN EL MUSEO

El Gusto en el Museo

el gusto en el museo

Quiksand Bold
EL GUSTO EN EL MUSEO
EI Gusto en el Museo
el gusto en el museo
Serenity
EL GUSTO EN EL MUSEO
El Gusto en el Museo
el gusto en el museo

Dunbar Text
EL GUSTO EN EL MUSEO
EI Gusto en el Museo
el gusto en el museo
Canto
EL GUSTO EN EL MUSEO
El Gusto en el Musco
el gusto en el museo

Semplicita Pro

EL GUSTO EN EL MUSEO

El Gusto en el Museo

el gusto en el museo

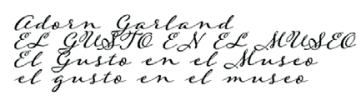

Figura 7. Experimentación con 8 familias tipográficas.

Fuente: Elaboración propia. 
Serenity medium

ABCDEFGHIJKLMNÑOPQRSTUVWXYZ1234567890 abcdefghijklmnñopqrstuvwxyzi!"\#\$\%\&/()='¿?'+* \{\}[]$, ; .:$

Proxima Nova Regular

ABCDEFGHIJKLMNÑOPQRSTUVWXYZ1234567890 abcdefghijkImnñopqrstuvwxyzi!"\#\$\%\&/()=' ¿?'+*\{\}[],;:

\section{Proxima Nova Bold}

\section{ABCDEFGHIJKLMNÑOPQRSTUVWXYZ1234567890 abcdefghijkImnñopqrstuvwxyz;!" \#\$\%\&/()=' ¿?'+*\{\}[],;:}

Figura 8. Detalle de las 2 tipografías seleccionadas: Serenity y Proxima Nova. Fuente: Brandbook de EGEEM.

\section{Elección cromática}

Estaba claro que este trabajo tendría dos tonalidades predominantes: azul y magenta, conclusión a la cual se llegó en una de las reuniones virtuales con el cliente, en donde se expresó la voluntad de mantener un vínculo cromático con el Máster en Gestión Cultural.

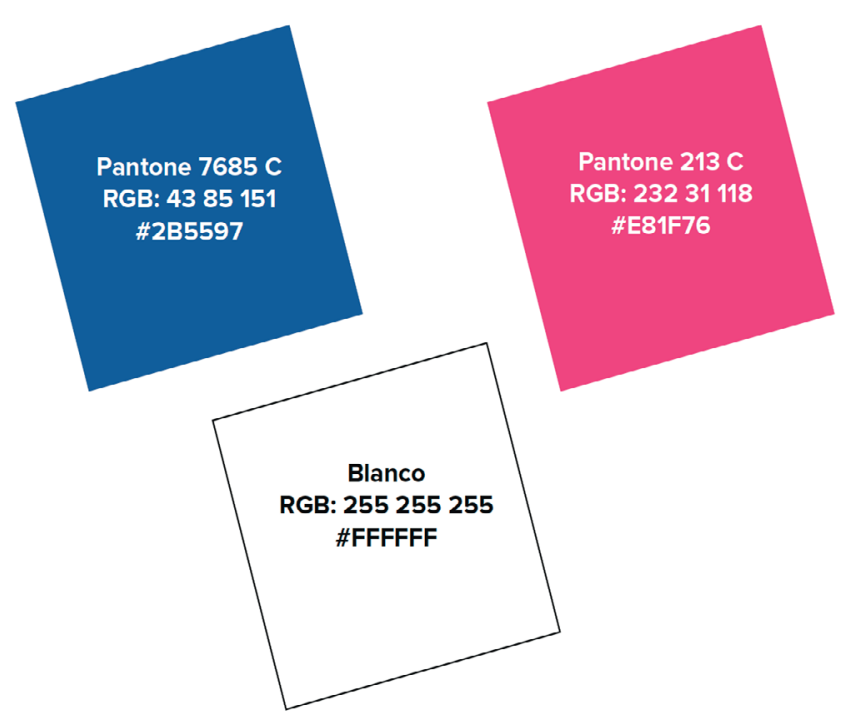

Figura 9. Elección cromática. Fuente: Brandbook de EGEEM. 
En el manual de identidad de EGEEM se expresa que:

"El color azul representa el color original que tenían los platos de cerámica de Manises, los cuales tienen un gran peso cultural e histórico en la gastronomía valenciana. El color fucsia representa la sensación de armonía y plenitud que sentimos al tener una buena alimentación, además, al ser un color enternecedor da sensación de bienvenida y amistad, siendo exactamente lo que todo museo quiere transmitir a sus visitantes. En adición, destaca las palabras "Gusto" y "Museo" para resumir las temáticas principales de la jornada".

\section{Bocetos}

Tomando como guía la intuición, se aborda la creación de propuestas preliminares que sirven para rejugar con las combinaciones de elementos, conceptos y requerimientos. No se busca lo
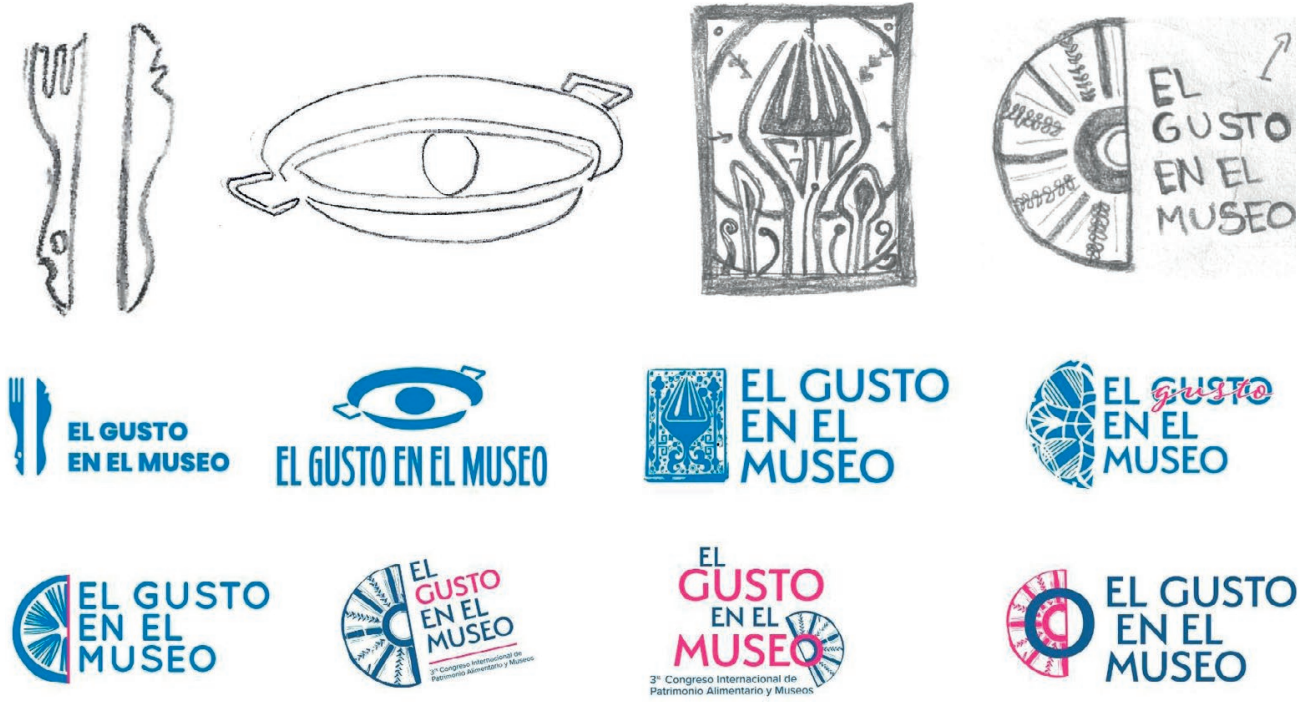

Figura 10. Selección de bocetos manuales digitales realizados para este desarrollo de marca. Fuente: Elaboración propia.
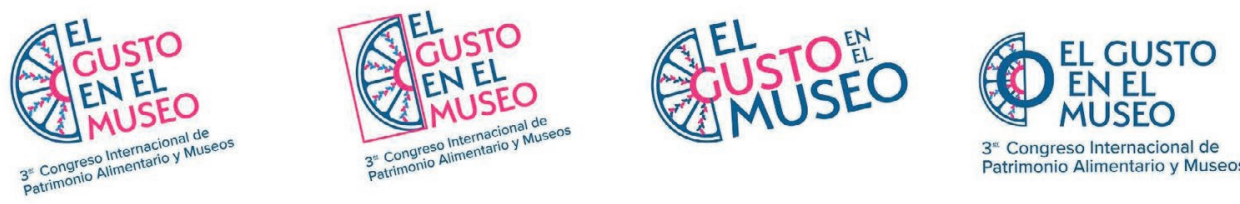

$3^{\text {s. }}$ Congreso Internacional de
Patrimonio Alimentario y Museos
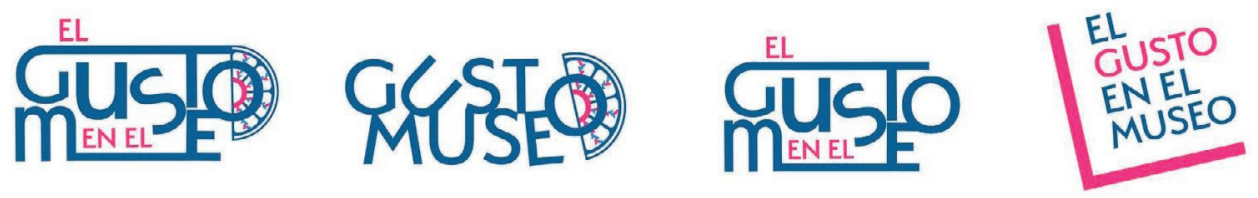

Figura 11. Propuestas iniciales.

Fuente: Elaboración propia. 
formalmente correcto, sino el flujo creativo, pues se entiende que estas son ideas crudas, que deben luego pasar por un posterior proceso de maduración.

Como se mencionó previamente, al momento de hacer la presentación al cliente se optó por un estilo democrático, que busca hacerle partícipe del proceso de toma de decisiones. Además, se optó por ponerles en contexto y presentar el proceso creativo desde sus inicios, en vez de concentrarse en la mera presentación de las propuestas finalistas. La siguiente figura muestra las propuestas presentadas como punto de partida.

\subsection{Fase de Emisión de Conclusiones}

Las conclusiones en diseño son el producto del proceso de iteración que surge de la retroalimentación recibida por parte del cliente y de la maduración de las ideas por parte del equipo creativo. Es la consolidación de propuestas formales o finalistas, las cuales son presentadas por el equipo de trabajo a los encargados de la toma de decisión.

En el caso de EGEEM, se presentaron tres finalistas, que pese a presentar personalidades totalmente distintas, tenían en común la misma aplicación tipográfica y cromática, variando la orientación de los caracteres y el isotipo. La siguiente imagen presenta el antes y el después, junto a la retroalimentación recibida.

\section{FEEDBACK}

EL

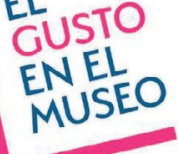

COLOCAR "MUSEO"

EN MAGENTA

\section{FEEDBACK}

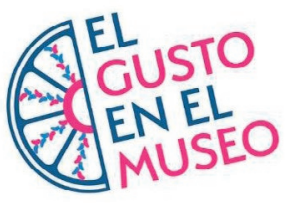

QUITAR MAGENTA

DEL PLATO

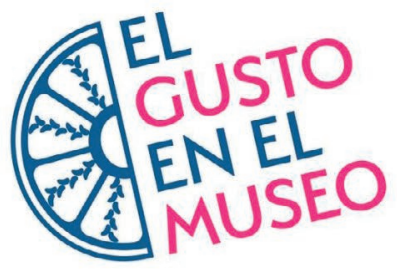

\section{FEEDBACK}

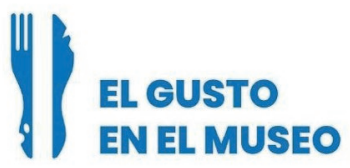

INTEGRAR CUCHARA Y

FORMAR ICONO MUSEOS

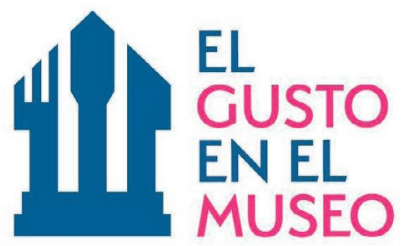

Figura 12. Iteraciones: antes y después de la retroalimentación.

Fuente: Elaboración propia. 

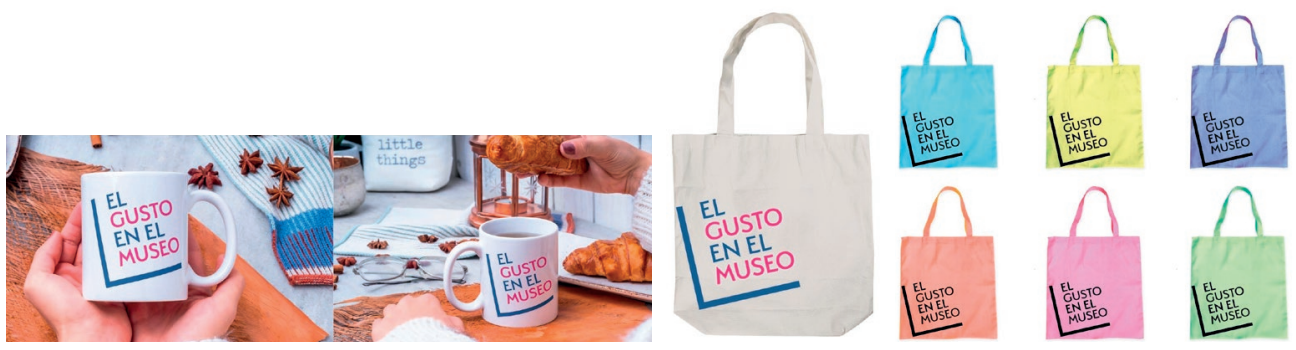

Figura 13. Prueba de concepto y aplicaciones de ejemplo. Fuente: Elaboración propia.

Tras un proceso de deliberación interna en el cual se ponderaron todas las propuestas, el cliente optó por seleccionar la primera opción. Como último paso y para validar su decisión antes de proceder con la definición del uso de la imagen creada en sus distintas ejecuciones, se presentó una prueba de concepto. En la misma se colocó, a modo de mockup, el finalista en dos aplicaciones comunes: una taza y una bolsa reutilizable.

\subsection{Fase de Publicación}

Los resultados de este trabajo pueden ser visualizados en el presente congreso y en el material vinculado al mismo. Sobre su significado, el manual de marca expresa lo siguiente: "la inclinación hacia la izquierda es un detalle que proporciona dinamismo moderno al logotipo. La esquina en forma de "L" representa el marco de un cuadro, el cual es un elemento característico de los museos tradicionales". Esta figura representa también la esquina de una mesa, lugar sobre el cual suelen disfrutarse los alimentos.

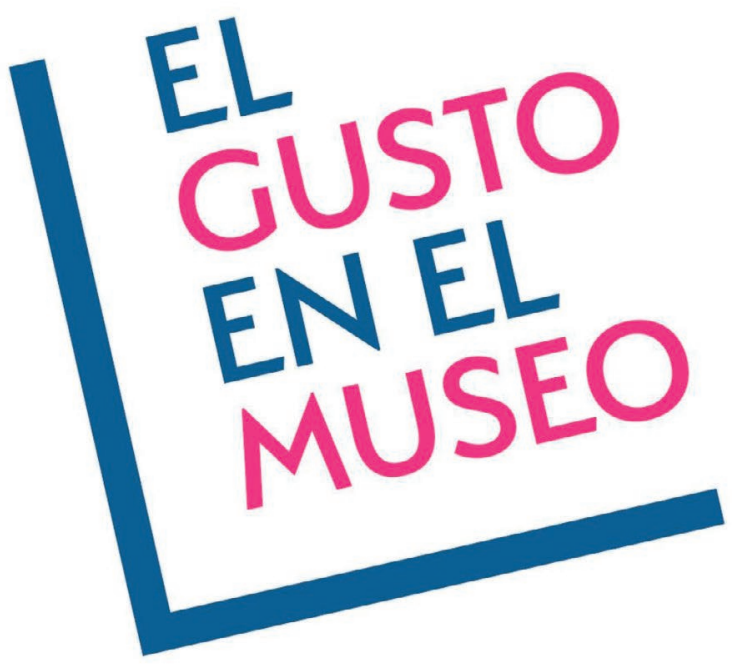

Figura 14. Logotipo seleccionado. Fuente: Elaboración propia. 


\section{Desarrollo del Manual de Marca o Brand Book}

Habiendo recibido el visto bueno del cliente, se procedió a la creación del manual de marca. También conocido como manual de identidad visual o de imagen corporativa, este instrumento tiene el propósito de mostrar la correcta utilización y aplicación de una identidad gráfica. Según lo descrito en el Manual de EGEEM: "el mismo contiene la información básica e imprescindible para el uso adecuado y reglamentario de los diferentes elementos del logotipo de El Gusto en el Museo, por lo que se sugiere leer detalladamente todo su contenido y seguir cada una de las indicaciones que se describen en los apartados de interés".

El objetivo de un brandbook es cuidar la imagen que se proyecta, sin dejar atrás aquellos aspectos que ayudan a fortalecer la cultura empresarial y el sentimiento de pertenencia. La utilidad de este instrumento radica en su claridad y en su capacidad de servir de guía ante los principales retos que se presentan al momento de ejecutar aplicaciones de una identidad visual. Su contenido varía según el tipo de proyecto y "la escuela" de la cual provenga el diseñador que lo creó. Sin embargo, es común que contenga total o parcialmente los siguientes componentes:

\section{Componentes del Manual de Identidad Corporativa}

- Símbolos de Identidad: logotipo original de reproducción; versiones en positivo, negativo, a línea; retícula de construcción; reducciones permitidas (100\%, 75\%,50\%, 25\%); disposiciones correctas e incorrectas; rotaciones correctas e incorrectas; fondos correctos e incorrectos; proporción de elementos, colores corporativos en Pantone, CMYK, RGB y tipografía corporativa.

- Papelería: tarjeta de visita, papel, sobre, folder con y sin bolsillo, portadas de carpetas, certificaciones, facturas.

- Impresos y publicaciones: etiquetas, literaturas, stickers, carteles, artes de prensa

- Uniformidad: rotulación de vehículos, uniformes del personal y equipo de trabajo, carné

- Material de promoción: lapiceros, camisetas, gorras, llaveros, memorabilia

- Señalética: con íconos y sin íconos

A modo de ejemplo, a continuación se presentarán algunos de los contenidos en el manual realizado por el diseñador Sergio Elías Taveras para el Congreso Internacional El Gusto en el Museo (EGEEM), incluyendo la Construcción gráfica, usos: permitidos y prohibidos,

\section{Construcción gráfica}

El siguiente gráfico, muestra la construcción de los elementos del logo sobre una cuadrícula en la que cada módulo $(X)$ representa una parte proporcional de la imagen.

El área de reserva es un espacio imaginario que rodea el logo y que protegerá la imagen de cualquier distracción visual. El área prevista para el espacio será proporcional a X.

\section{Usos: permitidos y prohibidos}

Dentro de los usos permitidos se encuentra la colocación sobre mágenes oscuras y elementos contratantes de fondo, fondos de color sólido con contraste, líneas y elementos decorativos al 

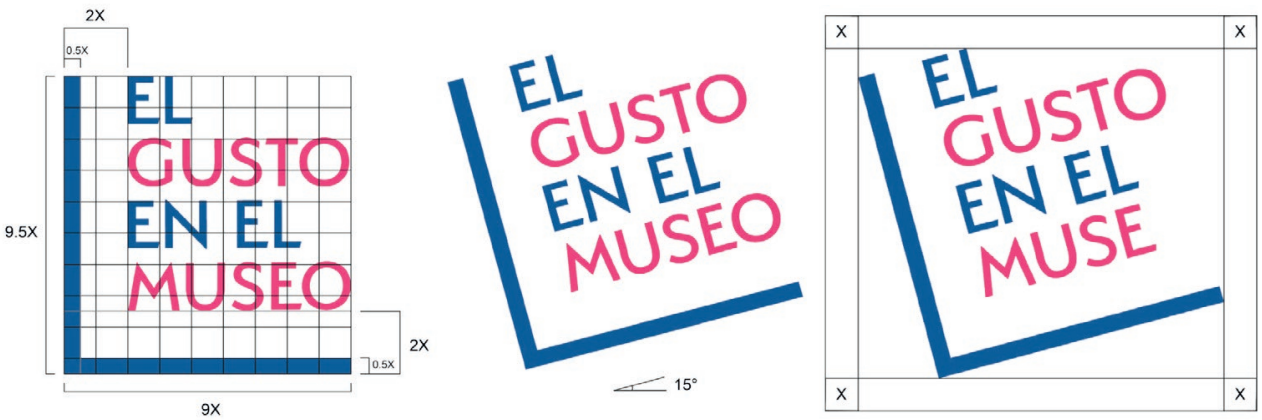

Figura 15. Construcción gráfica. Fuente: Brandbook de EGEEM.

lado de la esquina "L" del logo y disposición horizontal. Ejemplo de usos prohibidos son: alargar, aplanar, distorsionar, cambiar los colores, inversión de espacio y fondos con poco contraste.
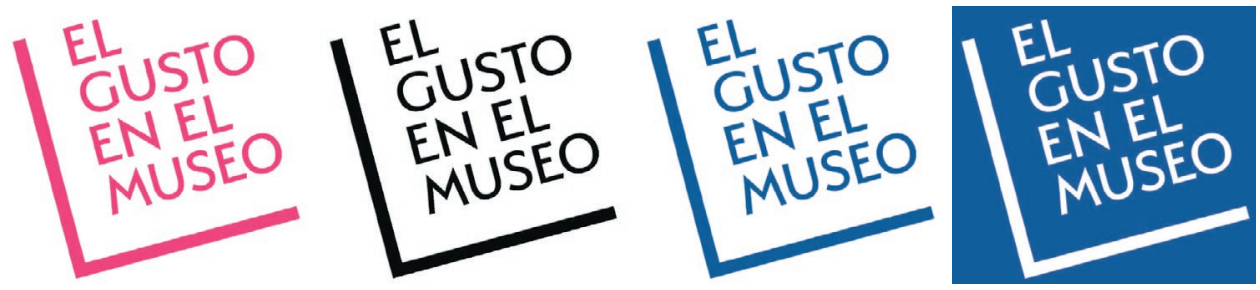

Figura 16. Versiones monocromáticas y en negativo. Fuente: Brandbook de EGEEM.

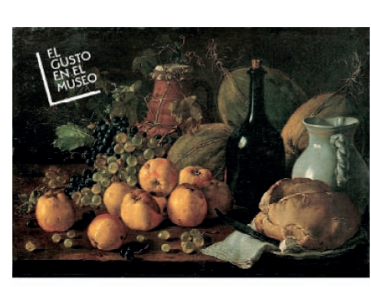

Imagen oscura y elementos contrastentes de fondo.

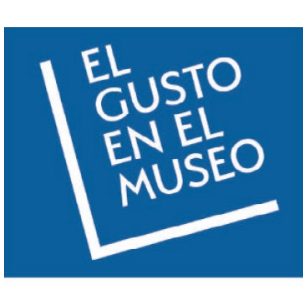

Fondos de color sólido con contraste.

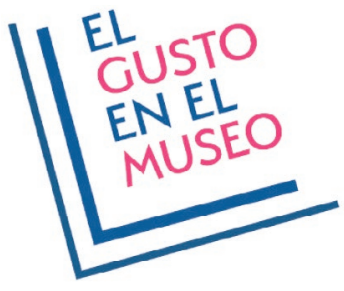

Líneas y elementos decorativos al lado de la esquina "L" del logo.

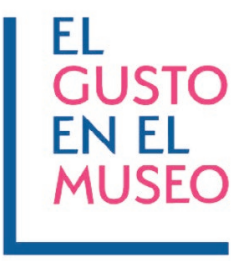

Disposición horizontal.

Figura 17. Usos permitidos.

Fuente: Brandbook de EGEEM.
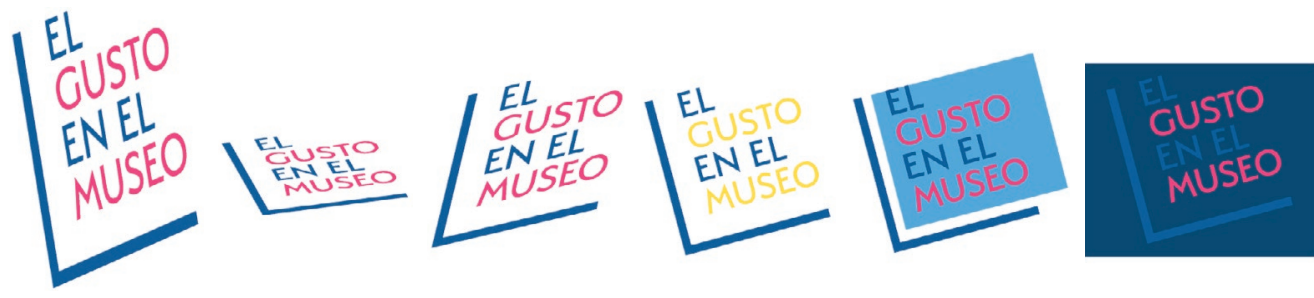

Figura 18. Usos prohibidos.

Fuente: Brandbook de EGEEM. 


\section{Ejecuciones}

Dentro de las ejecuciones incluidas en el Brandbook de EGEEM, se incluyeron la papelería, gafetes y material promocional como gorra, camiseta, pins y tazas, entre otros.

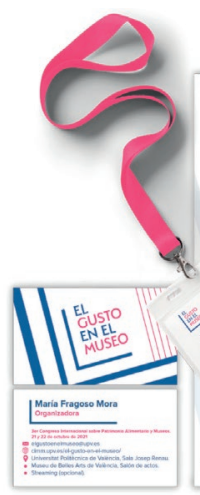

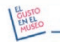

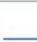
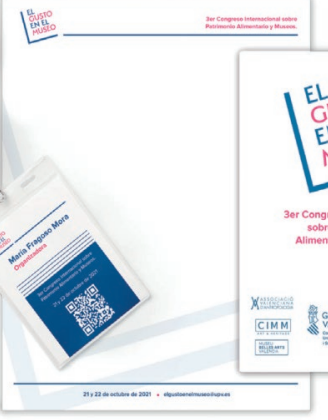
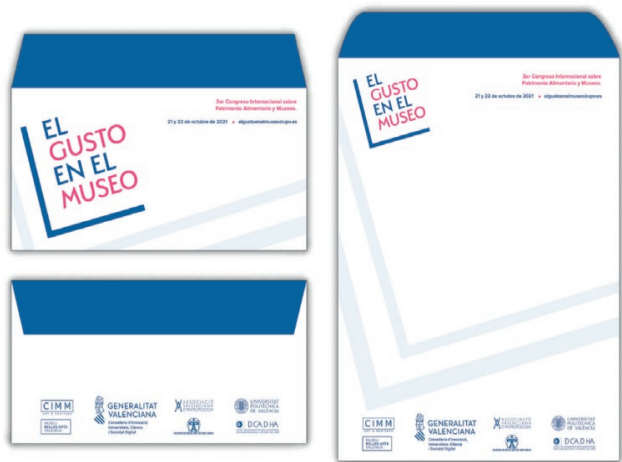

Figura 19. Papelería. Fuente: Brandbook de EGEEM.
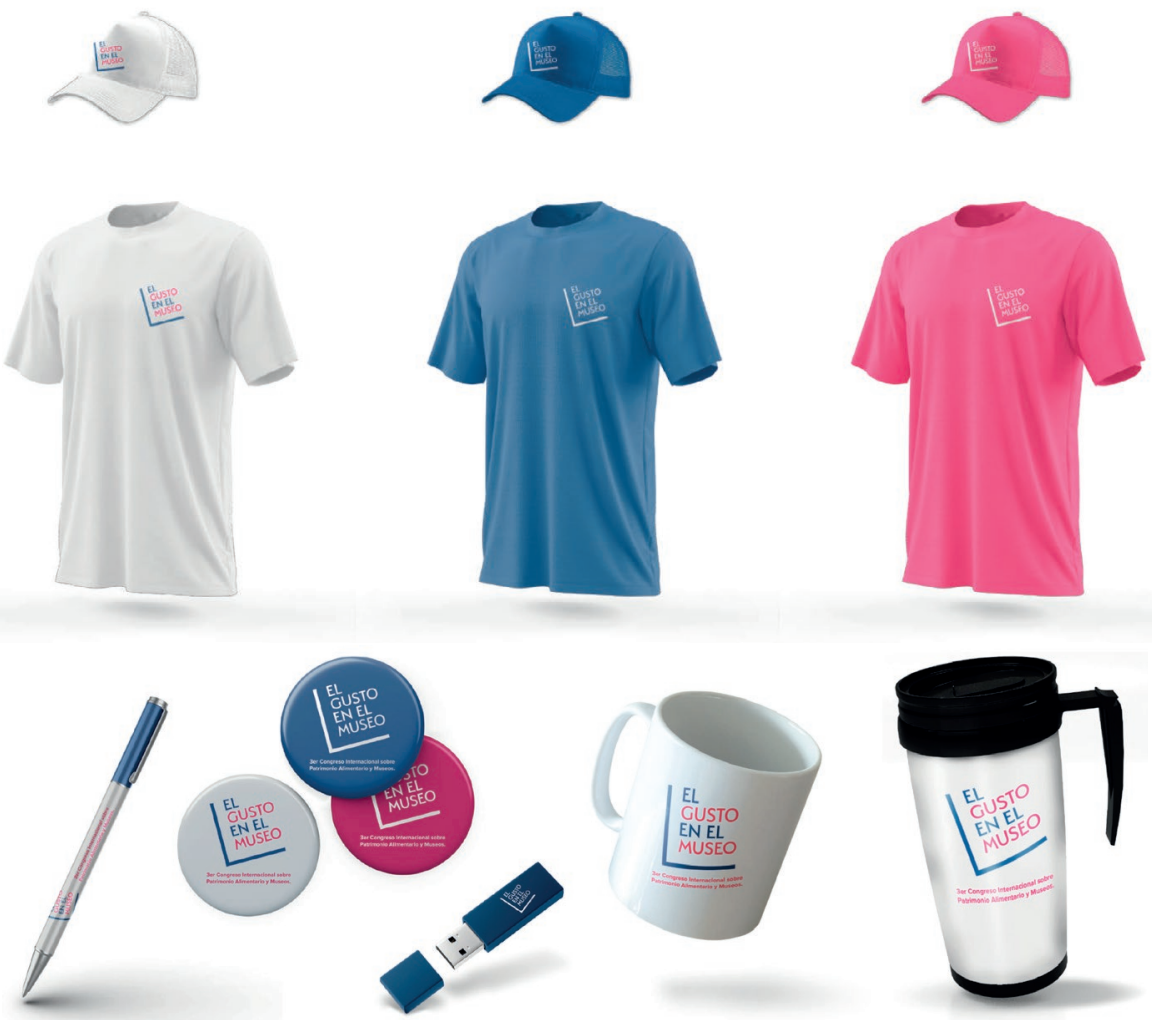

Figura 20. Material promocional.

Fuente: Brandbook de EGEEM. 


\section{Conclusiones}

El diseño gráfico, cuando se asume de forma responsable, es un proceso de investigación como cualquier otro, con la diferencia de que en vez de generar un resultado escrito y compuesto por palabras, obtenemos uno visual donde priman los píxeles, vectores y elementos cromáticos.

Según lo establecido al inicio, en el presente documento se procuró abordar, siguiendo los 5 pasos del método científico, preguntas en torno a la conexión que tienen el diseño gráfico y la producción intelectual con fines académicos. Se presentó el concepto de metodología del diseño, uniendo múltiples ideas en torno al mismo. Y, según lo expresado: se tomó como ejemplo la forma en que se realizó el abordaje del desarrollo de una identidad visual que vincula al diseño gráfico con la alimentación, la museografía y la producción académica. Permitiendo que la audiencia misma de su producto resultante, por tratarse en este caso de la imagen de este congreso, sea también testigo del proceso que llevó a su creación.

Al describir el proceso de creación de una identidad visual particular se utilizó la imagen del Congreso Internacional de Patrimonio Alimentario y Museos El Gusto en el Museo (EGEEM) como ejemplo y guía. Se presentó un análisis, desde la perspectiva metodológica, del proceso y motivaciones detrás de cada decisión dejando en el proceso pinceladas que pueden servir de guía para el desarrollo de proyectos con características similares. Así fue como una misma aplicación de diseño gráfico sirvió de ejercicio para la producción académica vinculada con la museografía y alimentación.

\section{Referencias}

BENNETT, A. (2006). Introduction: The Rise of Research in Graphic Design. Publicado en Design Studies. BONSIEPE, G. (1997). Design the blind spot of theory. Discursivity / Visuality.

COTTON, BOB. (1994). Biblioteca del diseño gráfico. Barcelona: Ed. Blume, Glosario.

CROSS, N. (1993). "Science and design methodology: A review". En: Research in Engineering Design, 5, 63-69.

GARGANTILLA, P. (2020). "¿Qué es el método científico? Estos son sus cinco pasos" ABC Ciencia. https://www.abc.es/ciencia/abci-metodo-cientifico-estos-cinco-pasos-201902170129_noticia.html [Consulta: Octubre 9, 2021].

HERNÁNDEZ SAMPIERI, R. (2014). Metodología de la Investigación. 6ta. edición. Mcgraw Hill Education. México.

MARTíNEZ SOSA, M. Y CALDERÓN MATA, L. (2007). "Propuesta de Proyecto Editorial para la ONG Hábitat para la Humanidad República Dominicana. Trabajo de Grado para optar por el título de Licenciadas en Diseño Gráfico. Universidad Apec.

MARTÍNEZ SOSA, M. (2003-2005) Apuntes de cátedra de las materias: Diseño Gráfico I, Prof. Genaro Philips. Universidad APEC. Licenciatura en Diseño Gráfico. Cuatrimestre enero- abril 2004.

Diseño Gráfico IV, Prof. Andrés Hernández. Universidad APEC. Licenciatura en Diseño Gráfico. Cuatrimestre enero- abril 2005. 
Psicología de la Percepción, Prof. María del Carmen Genao. Universidad APEC. Licenciatura en Diseño Gráfico. Cuatrimestre septiembre-diciembre 2005.

Tipografía, Prof. Fernando Rivas. Universidad APEC. Licenciatura en Diseño Gráfico. Cuatrimestre septiembre-diciembre 2004.

MEGGS, P. B. (2000) Historia del Diseño Gráfico. Ed. McGraw-Hill. México.

NOBLE, I., BESTLEY, R. (2005). Visual research an introduction to research methodologies in graphic design.

RAFF, J. (2012). "Theoretical Frameworks for the Conceptualization of Graphic Design in Use". En: Iridescent, 2(2), 10-21, https://doi.org/10.1080/19235003.2012.11428507.

SAMARA, T. (2005). Publication Design Workbook, A Real-World Design Guide. Ed. Rockport Inc., China.

TURNBULL, A. (2003). Comunicación Gráfica, Ed. Trillas. 